\title{
Role of the Government for Development of Sustainable Construction
}

\author{
Aneta Marichova
}

\begin{abstract}
In the last years questions related to sustainable development are particularly relevant. The construction market is usually identified as the first sector to face serious problems and requires special attention in implementing the idea. The main reasons for this assessment lie in the specifics of construction as an economic activity, the specifics of the construction product, the construction process, the specifics of organization and management of the construction company and the strong economic, social and environmental effect. The purpose of the proposed study is: 1) analysis of the problem of sustainability of the construction market, 2) the role and influence of the government for the development of sustainable construction.
\end{abstract}

Keywords - Construction Market, Role of the Government, Sustainable Construction, Sustainable Development

\section{INTRODUCTION}

The most frequently cited definition of sustainability is the one given in the report of the World Commission on Environment and Development (WCED) adopted in 1987 and entitled "Our Common Future". It defines sustainable development as a „development that meets the needs of the present without compromising the ability of future generations to meet their own needs" [1].

It is impossible to talk about sustainable development and to make a decision to protect the environment, reduce its pollution, without being taken into account economic and social consequences, and vice versa. Any sustainable economic solution must take into account both social and environmental effects. In other words, sustainable development integrates three dimensions - environmental, social and economic, affects the interests of society, business and the environment (also called the "three P's" - people, planet, profit), and the main goal is to minimize the negative impact on the environment and increase the benefits for both business and for society as a whole (Fig. 1.).

According to the report of the UN Commission on Environment and Development, it is clear that the sustainable development of countries and cities requires lower energy and material consumption, reduced pollution and better protection of natural resources and arable land. Poor building development models often lead to overcrowding and inefficient use of the scarcest resource - land. The result is greater energy consumption and travel time, loss of productivity, pollution of water sources, and loss of agricultural land, fragmented housing and financial burden on municipalities. In this sense, the idea of sustainable development directly affects the construction and activity of the construction firm. 


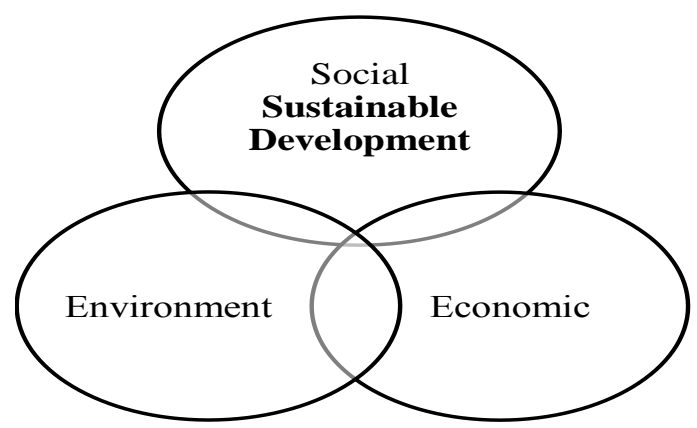

Fig.1. The three dimensions of sustainable development - environmental, social and economic

The trend for sustainable development also imposes the concept of a circular economy, which is becoming one of the main priorities of the EU. In December 2015, the European Commission published an Action Plan for the Imposition of a Circular Economy [2], placing it at the heart of sustainable development policy. The Commission proposes to rethink EU policy by introducing changes in the product life cycle stages: design (idea), production, consumption, waste management and re-treatment of secondary materials and also defines the priority areas (including construction) that face specific challenges.

The concept of a circular economy is an alternative economic model, which calls into question the traditional linear economy (model - take, produce and discard). In general, for many years it has focused on high productivity and low production costs, relying on the abundance of raw materials at a relatively low price. The typical linear model of the processes includes several stages - extraction of raw materials, production, consumption and disposal, destruction of products at the end of their life cycle. The concept of a circular economy imposes a circular model (also in construction), which includes all stages of the product life cycle: Raw Materials, Resources $\rightarrow$ Product Design $\rightarrow$ Production $\rightarrow$ Distribution $\rightarrow$ Consumption, Use, Reuse, Repair $\rightarrow$ Collection $\rightarrow$ Waste Management $\rightarrow$ Recycling $\rightarrow$ Creation Of New Raw Materials And Resources For Other Productions [3]. Therefore, the circular economy aims to ensure economic growth and reduce the negative impact on the environment by limiting the use of resources and reducing the amount of waste. The aim is to convert the products after their use into resources for other productions, through reuse, secondary production, recycling, waste reduction and other practices. In other words, the circular economy is striving for recovery (and not just waste management), better use of resources through sustainable consumption and production.

Interest in the circular economy is growing for various reasons. The most important of these are environmental factors in the first place - the growing scarcity of resources (especially strategic resources such as rare earth elements, for example) and the negative impact on the environment of traditional production and consumption. The main economic reasons are the volatile prices of resources and products and the potential for economic benefits (worth billions of euros) from the introduction of the concept of a circular economy in new markets. This model can create additional jobs in Europe, promote innovation that builds competitive advantages, increase the level of protection of people and the environment, and also provide consumers with more sustainable and innovative products through which financial savings are achieved and the quality of life is improved. From this point of view, the purpose of the proposed study is: 1) study of the problem of sustainability of the construction market, 2) what is the role and influence of the government for the development of sustainable construction. 


\section{THE PROBLEM OF SUSTAINABILITY OF THE CONSTRUCTION MARKET}

The construction market is usually identified as the first sector that requires special attention in implementing the idea of sustainable development. Sustainability raises the question above all: how long can nature and people withstand the environmental strain of construction and the use of new land for construction? The main reasons for this assessment are a consequence of the specifics of construction such as economic activity, the specifics of the construction product, the construction process, the specifics of organization and management of the construction firm and its economic, social and environmental effects:

1) From the point of view of the ecological effect, the requirements for sustainable development most directly affect the construction, because it is an activity with high resource intensity and related to use the most scarce resource - the land [4]. Construction firms spend a huge amount of resources - land and building materials, energy and water. The use of the final construction product accounts for a large share of environmental pollution and the generation of large amounts of waste. Given the statistics, reducing the amount of natural resources that buildings consume and reducing pollution and waste are crucial for future sustainable development. The construction sector itself accounts for 30$40 \%$ of world energy consumption, and over $70 \%$ of environmentally harmful emissions are due to electricity consumption during the operation of buildings. The volume of construction and demolition waste is one of the largest among the various types of waste. Construction and demolition produce one tonne of waste per person per year, which means 500 million tonnes across the EU each year. Valuable materials are not always identified and collected. Many of them can be recycled or reused, but the frequency of their reuse and recycling is not very high and varies considerably in the EU countries.

2) In terms of economic effect, construction is a structurally defining sector in any economy that affects overall economic development as directly (through the high relative share of GDP, value added and the large number of construction companies that provide employment), and indirectly along the lines of intersectoral connections (high costs for the purchase of raw materials, materials, electricity and other components used in the entire process of design, construction, maintenance and operation). The industry has an important role in maintaining production, employment, income, consumption levels and domestic demand at a higher level (and vice versa in the event of a decline in construction activity), which is why it occupies a special place in any government policy.

3) However, the construction market is important not only from an economic point of view, but also from the point of view of the social effect on consumers. This effect is determined and depends on the ability of the final construction product (buildings and facilities) with its characteristics to provide the desired quality of life, comfort in all its aspects - visual, thermal, acoustic, healthy microclimate of the premises inhabited by people [5].

The built facilities and infrastructure determine the degree of freedom and flexibility that society can enjoy. Through the construction activity the urban environment is built and developed. The introduction of new efficient technologies and intelligent investments ensure both the development of the building stock and the economy as a whole, and the integration of local communities. There are many examples in which the regeneration of buildings in backward areas (old industrial areas or ghettos of large cities) has led to a change not only in the quality of life of their inhabitants, but also to economic growth and socialization of isolated groups.

Large urban infrastructure projects and sustainable development programs have potential for significant impact on the development of transport systems, reduction of 
greenhouse gas emissions, alleviation of the traffic problem, etc. The long period (over 4050 years) of using the construction product makes it different from the products of any other industry, and the place on the construction market - unique. At the same time, these features and specifics pose the problem of finding a successful model for effective longterm management and maintenance, which reduces the investment/costs of owners for reconstruction and renovation of the building stock and indirectly affects and improves the characteristics of construction.

4) The most worrying reason why construction is defined as the main industry creating problems for sustainable development is the bad reputation in terms of propensity and development of innovation, i.e. the lack of change. This is shown by statistics, where innovations are reported on the basis of standard indicators. Most often, the main indicator used is the relative share of costs that companies in a given industry and the industry as a whole make for research and development. In the construction of EU countries, this indicator averages around $0,25 \%$, which is quite low compared to other industries.

On the other hand, however, if the specifics are taken into account, innovations in the construction market must be considered as composed of [6]: innovations at industrial level (changes in norms and standards, sustainable construction), business-level innovation (more efficient use resource throughout the construction process, recycling and reuse)and project-level innovations that have a major impact on productivity and efficiency the construction process and the industry as a whole.

The first international conference on sustainable construction was held in 1994. In 1998, the International Council for Research and Innovation in Building and Construction CIB defined sustainable construction as the need to create and maintain a healthy building environment based on the principles of efficient use of resources and ecology [7], and is later seen as a holistic process that aims to restore and maintain harmony between the natural and the built environment and to create settlements, which affirm human dignity and promote economic justice [8]

Sustainable construction develops on the following seven principles:

1) Reduction of construction resources.

2) Resource reuse.

3) Use of recycled materials.

4) Protection of the natural environment.

5) Exclude the use of toxic materials.

6) Guaranteed low costs for maintenance of construction sites.

7) Emphasis on quality.

These principles apply to all stages of the life cycle of the building, to the resources needed for construction, and are also leading in the management of construction processes, which are based on overall quality management.

The development of sustainable construction creates and imposes new terms, such as: high-tech, green, sustainable and passive buildings and high-tech, green, energy efficient and sustainable materials and technologies. They are usually used interchangeably, but only the term "sustainable" contains and shows equality of environmental, social and economic issues of construction and construction sites in the context of modern principles of sustainable development.

The concept of sustainable (and circular) construction is increasingly affecting the construction market, so detailed knowledge of the principles and requirements are a must for construction professionals and construction companies that design and build the relevant sites, for companies whose activities are related to management and maintenance of buildings and real estate management. However, projects and completed objects that 
meet these standards are still rare and there is still no widespread application of the principles of sustainability in the construction market. There are barriers that prevent sustainable construction from becoming a dominant trend in the industry. The reasons are related to not very strong interest from investors, lack of training and knowledge for sustainable development and sustainable construction, the inherent conservatism in the education of architects and civil engineers, inadequate funding for research in this area,financial problems (higher cost). In addition, there is a lack of a well-defined set of norms, standards and sustainable construction practices that can be used in projects. Information on procedures related to the inclusion of environmental, economic, social issues and relevant assessments in construction is limited and formally structured.

Sustainable construction requires a holistic approach - from the stage of design, construction, operation and demolition of a building, recycled and reused materials and significant changes in the overall organization of construction, both at market and company level, in the active role of the government.

\section{ROLE OF THE GOVERNMENT FOR DEVELOPMENT OF SUSTAINABLE CONSTRUCTION}

The role and influence of the government for the realization of the principles of sustainable construction is in the following several directions:

The government (public sector) is a major player in the construction market (especially in the civil engineering market) and its main task is to ensure the optimal combination of input resources and efficient use of technology to reduce losses and increase the benefits for society. By definition, a competitive market supported by the state ensures the efficiency of the scarce resources used and sustainable economic development. As a regulator of the construction market, the government seeks to reduce market inefficiencies, which is a factor in creating ineffective competitive advantages for certain selected companies. It is in the interest of the whole society to exercise constant control over the unethical behavior of firms, agreements that restrict competition and possible policies of price coordination and the creation of cartels.

The government develops the main policies, programs on issues that directly and indirectly affect construction, but at the same time go beyond the industry, such as energy efficiency, waste management and climate change.

With their activities, the government at national or local level must:

- To ensure cooperation, interaction and equality of all interested companies and to creates conditions for strategic partnership.

- To ensure coordination of the various programs and financing of interconnected activities and not of individual activities and projects that are isolated from each other.

- To maintain the necessary infrastructure - transport, social and opportunities for continuous development, training and retraining of the required workforce.

- To ensure funding and incentives for research, development and active participation of a construction firm in this process.

- To improve waste management in the construction sector by building a construction waste sorting system, that can have a significant impact on development of the circular economy [9].

- To provide opportunities for recovery of valuable resources through the dissemination and application of best practices in this field. 
- Given the long life cycle of buildings, it is essential to encourage design improvements that will reduce the negative impact on the environment and increase the durability and recyclability of their components.

- To develop a system of indicators for assessing the environmental, economic and social indicators throughout the life cycle of the construction product and promoting their use.

All these activities of the state must be directed in the phase preceding the destruction of construction sites in order to promote valuable and voluntary recycling in the sector. The main goal is to improve the quality of recycled construction materials and build consumer confidence in them.

The government is a major customer in the construction market. In its role as a client, the government with its requirements can make the greatest progress in the implementation of the sustainable development program, because it is responsible for the construction of public buildings and infrastructure. Over $50 \%$ of construction orders come from one source - the state and municipalities, mainly funded by the EU. EU policy is aimed at increasing the obligation of state institutions to comply with the principles of sustainable construction, which is bound by an EU directive.

As energy efficiency is an essential part of the overall idea of sustainable construction, the government must ensure the rehabilitation and renovation of the existing old building stock by an average of $3 \%$ per year. Given that a $1 \%$ increase in energy savings reduces gas imports by $2,6 \%$, it is clear why the ambitions of the EU and each individual country in this regard are so important.Financial mechanisms, incentives and the mobilization of financial institutions for the renovation of buildings in order to improve energy efficiency should play a central role in the national long-term renovation strategy. These measures should include the promotion of energy-efficient mortgages, the certification of energy-efficient refurbished buildings, the promotion of public investment in energy-efficient buildings, through public-private partnerships or the conclusion of energy-saving contracts with guaranteed results, the reduction of investment risk, providing accessible and transparent tools for consultation and assistance.

Due to the instability of the construction market and the strong macroeconomic effect of its development, it is subject to a special macroeconomic policy. It includes both fiscal (conducted by the state as an economic entity) and monetary (conducted by the Central Bank) policy, which aims to stimulate the activity of the construction market and which has positive direct and indirect effects on the overall economic development, but at the same time these actions are objectively limited by the capabilities of each country [10].

In the new dynamic conditions, however, the more complex problem is to what extent these actions will be an incentive for supply changes over the long term. The change in supply is a function mainly of increased government spending and investment in education and research related to sustainable economic development and construction, support for innovation in small and medium enterprises, protection of intellectual property, building effective links between companies and the public sector. These are factors that ensure the development of the internal intangible assets of the construction firm, i.e. learning and development of knowledge, research and development, the system of additional incentives and motivation of staff, incentives and support for complementary and interconnected activities in the vertical supply chain, support for venture capital in small innovative companies, etc., which ultimately account is a strong factor for the accelerated development of sustainable construction. 
In accordance with the basic principles of sustainable construction, the government must develop the following clear and precise criteria for a comprehensive sustainable approach that can be easily applied by the construction firm:

1) Location. Promotion of construction on land already used for the same purpose, on contaminated terrains and terrains of low ecological value.

2) Water. Promoting reduction of water consumption, implementation of systems for timely detection of leaks, reuse of drinking water for other needs.

3) Energy. Improving the overall energy efficiency of the building, reducing carbon dioxide emissions from energy production.

4) Transport. Construction near public transport, the presence of bike lanes and walkways.

5) Construction materials. Use of certified, renewable and harmless construction materials.

6) Health and tone. Taking into account the influence of internal and external factors (light, noise, air quality, thermal comfort, etc.) on humans.

7) Waste. Recycling of waste, disposal in a safe place, use of recycled materials, etc.

The main goal of the government as a major player in the construction market should be the introduction of a mandatory requirement for the use of Building Information Modeling (BIM) in the development and implementation of all projects/objects that it buys in the public sector. BIM is a digital representation of their physical and functional characteristics based on information and knowledge about the respective construction site, which is a reliable basis for making effective decisions throughout the life cycle - from the idea, the concept, the project, the operation until the destruction. The key word in BIM is "information" because it integrates data related to cost, time, energy and sustainability. The information modeling of the buildings allows to develop a virtual information model with the simultaneous participation of the whole design team (architects, landscape architects, surveyors, constructors, civil engineers, etc.), as each specialist adds specific data from the respective field to the unified model. This model is provided for analysis, evaluation by the investor, suppliers, the contractor and subcontractors, and finally the owner/manager of the building. As everyone involved in the construction process provides detailed information from the outset, this reduces the asymmetry and information loss that traditionally occur when a new participant in the vertical chain acquires "ownership" of the projects/objects. In other words, information modeling provides a complete picture and complex analysis of the life cycle of the construction product (from idea to demolition and reuse), which allows to increase productivity in the design, construction and management of buildings and facilities. In addition, the system is seen as an effective way to integrate and work together the construction team to reduce errors and unnecessary changes, to reduce transaction costs in the transmission of information within the vertical supply chain. In short, it simplifies and integrates the processes of design, delivery, construction, asset management, waste management, recycling, reuse and creates conditions for the development of circular construction.

The main task for the government as an economic entity that must ensure sustainable development is the creation of the necessary state standards and requirements for sustainable construction, as well as mechanisms, models for renovation, guarantee funds, regulations, fiscal incentives for investors and consumers of products of sustainable construction. It is essential to accelerate the process of building certification based on established methods for assessing sustainable construction. The main methods used are BREEM (BRE Environmental Assessment Method) and LEED (Leadership in Energy and 
Environmental Design), which are internationally recognized certification system applied throughout the life cycle of buildings - design, construction, operation.

All these policies and the accompanying building standards must also be supported by financial incentives (tax breaks and loans on favorable terms for sustainable construction). It is necessary to intensify the activities of banks, insurance and pension companies, which are still very passive participants in this process.

The practice in different countries proves the effectiveness of government policy aimed at stimulating construction on the principles of sustainable construction. This imposes the need for a more active role and intervention of the government in this market in a completely new, different aspect of the direct stimulation of civil engineering sites. The emphasis should be on effective change of the industry and the activity of the firms by applying an integrative approach to different activities and projects, which are interconnected, complementary (Fig.2).

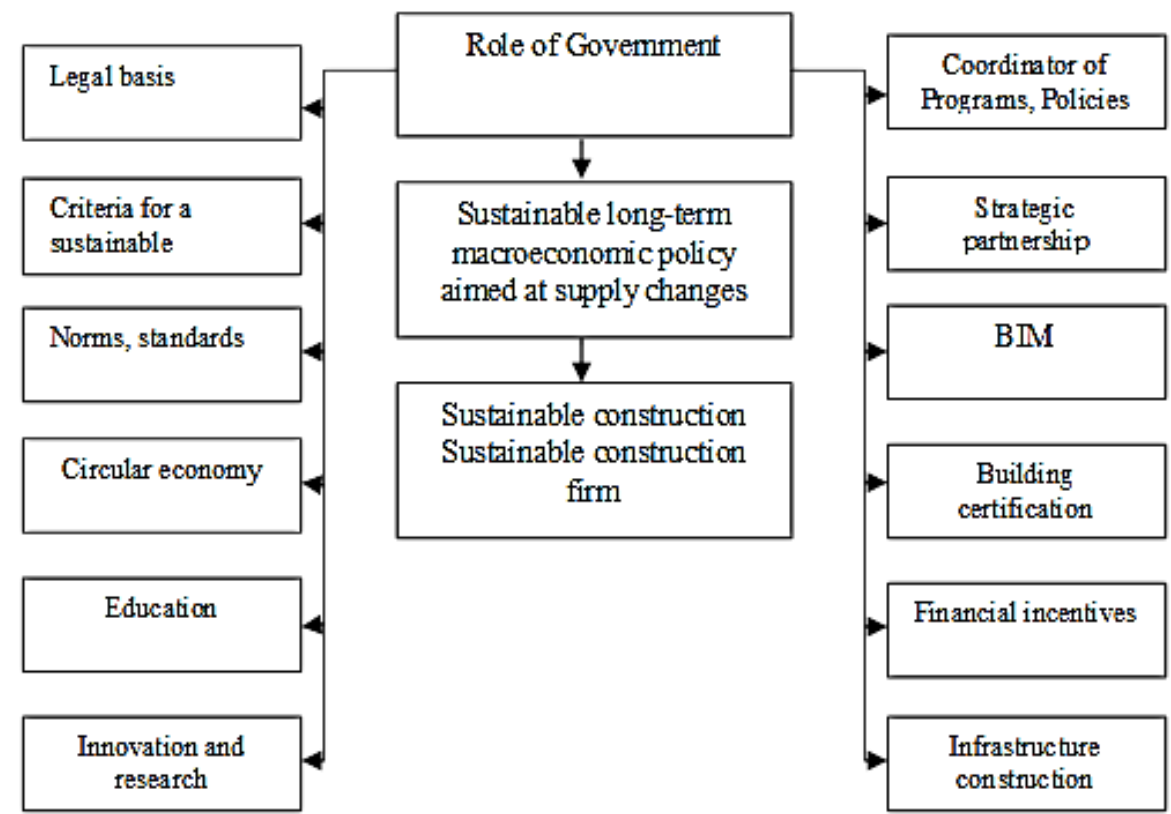

Fig.2. Main directions of the government's activity for development of sustainable construction and creation of a sustainable construction firm

\section{CONCLUSIONS}

Sustainable development and sustainable construction integrates three dimensions environmental, social and economic and affects the interests of society, business and the environment ("three P's" - people, planet, profit). In the study, the author aims to analyze the specifics of the problem of sustainability in the construction market, and the role and influence of the government for the development of sustainable construction.

Sustainable construction is seen as a holistic process that aims to restore and maintain harmony between the natural and the built environment, and to create settlements that promote human dignity and promote economic justice. The problem of sustainability poses new challenges and requirements for construction and construction firms. 
The difficulties are caused by the specifics of construction such as economic activity, the specifics of the construction product, the construction process, the specifics of organization and management of the construction company, as well as the fragmented nature of the construction market, which limits opportunities for higher efficiency and change. The sustainability of the construction market raises the question above all: how long can nature and people withstand the environmental strain of construction? The issue is extremely important because construction is an activity with high resource intensity, related to the most scarce resource - land, large volume of waste, low propensity to innovate (a major factor for achieving sustainability), a strong impact on overall economic development and with a strong social effect on consumers.

There are barriers (limited knowledge of conservatism, financial reasons, etc.) that prevent sustainable construction from becoming a dominant trend in the industry. Still rare are projects and realized objects that meet sustainable principles and standards. The absence of an adopted uniform standard, developed adequate legal norms, guidelines for design, construction and maintenance of sustainable construction sites does not allow effective cooperation of all participants in the vertical chain of construction activities and leads to demotivation of all participants in the process - investor, owner, user, designer, builder, site manager, etc.

For these reasons, active government intervention is needed, pursuing a purposeful and consistent policy that unites all participants at all stages of the construction process. Feedback is needed on the process of creating sustainable construction objects, analysis of financial costs for their construction, maintenance and management of buildings, certification to support the implementation of future projects.

The public sector is a major player and regulator in the construction market (especially in the civil engineering market). In its role as a client, the government with its requirements can make the greatest progress in the implementation of the sustainable development program, because it is responsible for the construction of public buildings and infrastructure.

According to the author, the main directions of government intervention in the construction market are: development and implementation of the principles, the necessary standards and requirements of sustainable construction, introduction of a mandatory requirement for the use of Building Information Modeling (BIM) in the development and implementation of all projects/objects, which it buys in the public sector, as well as the mechanisms, renewal models, guarantee funds, regulations, fiscal incentives for investors and consumers of sustainable construction products.

Macroeconomic policy must be aimed at stimulating the development of sustainable construction. Short-term fiscal and monetary measures aim to stimulate demand (by increasing government spending on public buildings) and reduce the impact of cyclical fluctuations in the construction market. In modern conditions, government policy should be aimed at creating conditions for long-term changes in supply that will ensure sustainable development and sustainable construction (increasing government spending and investment in research and education, innovation, building effective links between companies and the public sector and enforcement of mandatory standards, sustainability requirements).

The government policy for support of the sustainable construction and the adequate management of the construction object during its whole life cycle is important for the future development of the construction market and the construction firm, which ensure efficient and healthy living environment, environmental protection, efficient use of scarce resources, with future generations in mind. 


\section{REFERENCES}

[1] WCED, (1987), Our Common Future, The World Commission on Environment and Development, NY Oxford University Press, pp.43

[2] EC, (2015), Communication from the Commission to the European Parliament, the Council, the European Economic and Social Committee and the Committee of the Regions: Closing the loop - An EU action plan for the Circular Economy, https://ec.europa.eu/transparency/regdoc/rep

[3] European Commission, (2015), European Business Awards for the Environment, Iss.21, Dec.

[4] EU, (2012), Directive 2012/27/EU of the European Parliament and of the Council of 25 October 2012 on energy efficiency

[5] Doneva D., (2014), Socio-economic aspects of sustainable development in Bulgaria, Visnyk of the Lviv University, Series International Relations, No Issue 35, pp. 190-199, ISSN 2078-4333.

[6] Sexton M., Abbott C., Barett P., Ruddock L., (2007), Hidden Innovation in construction, Second International conference World of construction project management, Research Report, NESTA, University of Salford, (7/20), pp.1-21

[7] CIB, (1999), Agenda 21 on sustainable construction, Report Publication

[8] Du Plessis C., (2002), Agenda for Sustainable Construction in Developing Countries: A discussion document, Report for CIB and UNEP

[9] EC, (2015), Communication from the Commission to the European Parliament, the Council, the European Economic and Social Committee and the Committee of the Regions: Closing the loop - An EU action plan for the Circular Economy, Construction, pp.21, https://ec.europa.eu/transparency/regdoc/rep

[10] Marichova A., (2019), Impact of Macroeconomic Policy on the Development of the Construction Market. Study of the Example of Bulgaria, International Journal of Innovative Science and Research Technology (IJISRT), Vol. 4, Iss. 11, Nov., pp. 207-216

\section{Note:}

Aneta Marichova - University of Architecture, Civil Engineering and Geodesy, 1, Hristo Smirnensky Boulevard, 1046-Sofia, Bulgaria (e-mail:aneta.marichova@abv.bg, marichova_fte @uacg.bg) 